\title{
Sistema Generativo Evolutivo como Método no Processo Criativo
}

\author{
Evolutionary Generative System as a Method on Creative Process
}

\author{
> Jarryer Andrade De Martino \\ UNICAMP, Brasil \\ jarryer_martino@hotmail.com
}

\author{
> Gabriela Celani \\ UNICAMP, Brasil \\ celani@fec.unicamp.br
}

\begin{abstract}
This paper presents the evolutionary algorithms associated with a generative system as a design method for creating a roof. The flexibility of the system allowed the generation of five experiments with different formal arrangements, contributing to the development of the creative process by obtaining unexpected results and more efficient. The paper presents a brief conceptual description of the evolutionary generative system, the description of the method used and the analysis of results.
\end{abstract}

Keywords: Evolutionary algorithms; Parameterization; Creative process; Optimization; Diversity

\section{Introdução}

Os Algoritmos Evolutivos (AE) tiveram a sua origem na ciência da computação, na área da inteligência artificial, reproduzindo computacionalmente o processo evolutivo fundamentado na Teoria de Darwin. A sua principal característica é a reprodução artificial dos mecanismos evolutivos que possibilitam o comportamento adaptável (adaptive behavior). Assim como na Natureza, esse processo é caracterizado pela integração e interação entre o grande número de espécies e suas variações, que buscam atingir o equilíbrio com o meio através de uma disputa pela sobrevivência dos mais aptos. É este o principal enfoque para a utilização dos AE, ou seja, a busca por soluçóes que resolvam e satisfaçam simultaneamente e satisfatoriamente os diferentes objetivos que envolvem um determinado problema (Floreano \& Mattiusi, 2008).

Os AE no processo de projeto precisam ser estruturados conforme o pensamento algorítmico, embasado em variáveis, regras, procedimentos e restriçóes que permitirão a criação de um sistema parametrizado capaz de se adaptar ao meio. A ideia de algoritmo se resume a um conjunto finito de regras ou operaçôes precisas, inequívocas e simples, que ao serem seguidas conseguem conduzir à execuçáo de uma ação (Terzidis, 2009). A modelagem paramétrica e associativa corresponde a um sistema constituído por partes que se inter-relacionam e sofrem um auto ajuste quando uma variável é alterada, sem perder a sua estrutura principal (Woodbury, 2010). A ideia de sistema corresponde aos múltiplos agentes interagindo dinamicamente (Alexander et al., 2013). Dessa forma, o sistema generativo é capaz de contribuir no processo de geraçáo de soluçóes, participando indiretamente no processo de obtenção do produto.

O uso de um método evolutivo como sistema generativo possibilitará a avaliação e seleção das soluçôes que melhor satisfazem a um determinado problema, realizando uma busca exaustiva pelo campo de soluçóes, possuindo como componentes a representaçáo dos indivíduos, a população inicial e as descendentes, a função de avaliação (fitness function), os mecanismos de seleçáo e os operadores de diversidade (mutação e recombinação) (Bentley, 1999). O elemento arquitetônico ou indivíduo (termo recorrente na área da computaçâo evolutiva) pode utilizar os parâmetros reais que envolvem um projeto, como a dimensão para o comprimento, largura, altura, coordenadas de posicionamento, ângulos, entre outros. Estas características serão organizadas conforme o modelo cromossômico inspirado na codificação dos seres vivos, o DNA. A utilização dos parâmetros reais, ao invés de sua substituição por valores codificados, permitirá a obtenção de maior grau de precisão nos resultados, pois os valores são diretamente manipulados, evitando o processo de mapeamento, codificação e decodificação. A populaçáo inicial geralmente é constituída por indivíduos escolhidos aleatoriamente a partir de um conjunto de possíveis soluçôes até completar um número determinado pelo projetista. Após essa composição, é necessária a definição algorítmica para comandar a execução dos procedimentos capazes de gerar a próxima população, geralmente mantendo sempre o mesmo número de indivíduos nas geraçóes, resultando na completa substituiçáo da geraçáo velha pela nova. A mutação e a recombinação são os operadores responsáveis por gerar 
a diversidade nas populaçóes, contribuindo para a exploraçáo do espaço de soluçóes, pois a partir da alteraçáo provocada nos genes dos cromossomos dos "indivíduos pais", ou na combinação entre eles, surgirão os "indivíduos filhos", que correspondem a diferentes pontos localizados no espaço de soluçóes. Estes operadores são os responsáveis pela varredura no campo de soluçóes, contribuindo para a busca das melhores soluçóes (Kallel et al., 2001), por isso eles são considerados os elementos que caracterizam os métodos evolutivos (Eiben \& Smith, 2010).

Dessa forma, este artigo apresenta um exercício de projeto que demonstra a aplicação do método evolutivo, possuindo como problemática a necessidade de negociação entre duas variáveis conflitantes. O exercício corresponde ao projeto de uma cobertura complementar a uma edificação existente, mantendo o sombreamento de uma área já coberta, mas que recebe insolação no período das 14 às $16 \mathrm{~h}$ devido a uma abertura lateral. Por isso, os experimentos foram realizados considerando o solstício de verão na data de 23 de Dezembro de 2013, às 16h, horário em que ocorre a maior incidência solar na regiáo especificada. $\mathrm{O}$ desenho da estrutura apresenta aberturas ao longo da superfície, contribuindo para a ventilação natural. Assim, a solução ideal deverá apresentar a maior área de sombreamento com o maior valor para a somatória dos comprimentos que definem as dimensões das aberturas, duas variáveis contraditórias que deverão ser negociadas, situação propícia para o uso dos AE.

\section{Metodologia}

A implementação computacional do projeto ocorreu através do plugin Grasshopper (editor gráfico de algoritmos) para o programa Rhinoceros da McNeel (programa de modelagem geométrica tridimensional baseado na tecnologia NURBS), sendo utilizada a ferramenta Galapagos para a implementação dos AE, e o Geco (add-on responsável pela integração com o programa Ecotect da Autodesk, para a realização das simulaçóes de sombreamento). Para isso, o código que representa o projeto foi estruturado em três blocos, o primeiro constituído por elementos construtores da forma e as suas relaçóes paramétricas, o segundo responsável pelos AE e os critérios para a avaliação das soluções, e o terceiro relacionado à simulação da insolação. A configuração padrão adotada para os $\mathrm{AE}$ dos cinco experimentos considerou: a maximização do valor de fitness, o fim da execução do algoritmo ao atingir 50 geraçóes estagnadas, populaçóes compostas por 50 indivíduos em cada geração (a primeira configurada para possuir o dobro de indivíduos), taxa de permanência de 5\% dos melhores indivíduos de uma geraçáo para a outra, e o cruzamento entre os indivíduos que possuírem 75\% de grau de parentesco (semelhança entre as suas características).

A implementação do projeto em uma ferramenta paramétrica contribuiu para a adoção de uma metodologia com caráter experimental, pois através da reconfiguração do modelo paramétrico foi possível gerar cinco experimentos distintos, permitindo a posterior análise dos resultados (Groat \& Wang, 2013). Para o desenvolvimento do exercício projetual foram adotadas duas abordagens para a concepçáo da cobertura, uma parcialmente parametrizada (com variação apenas no dimensionamento das aberturas), e a outra totalmente parametrizada (permitindo variaçóes na forma

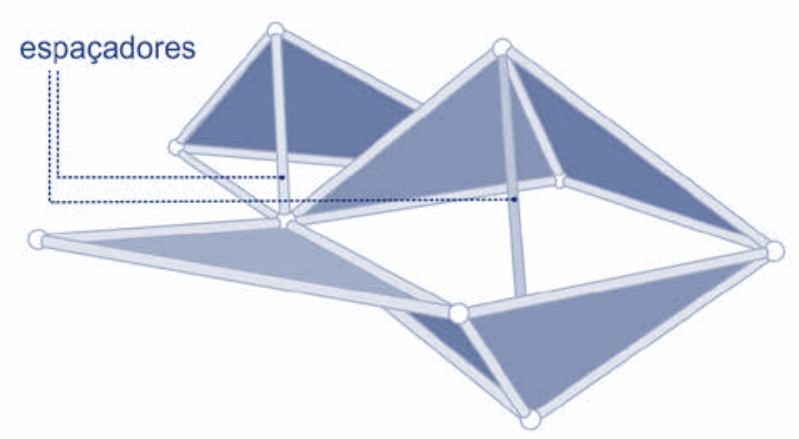

Figura 1: Detalhe da estrutura com os espaçadores. Elaborado pelos autores.
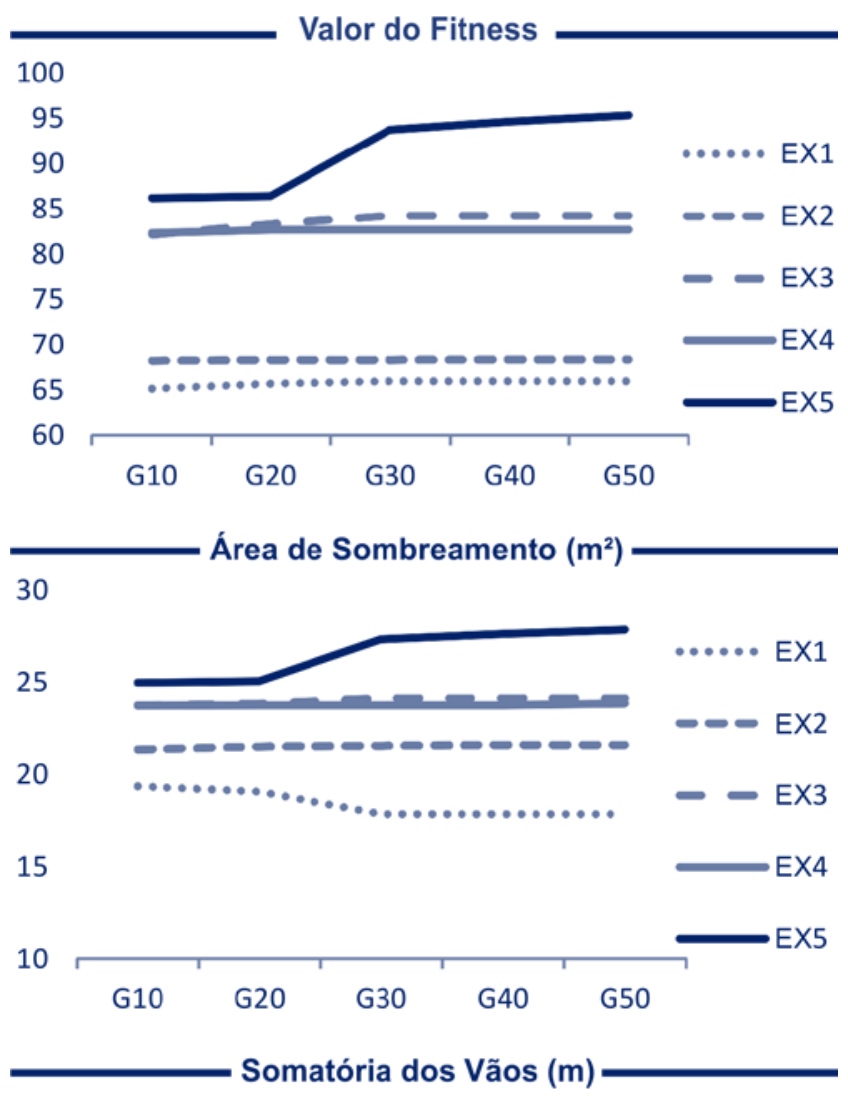

14

12

10

8
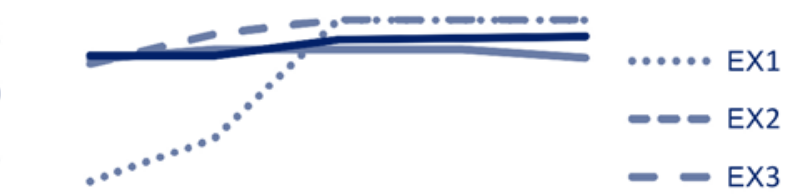

6

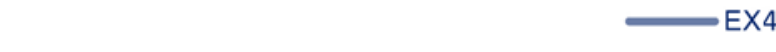

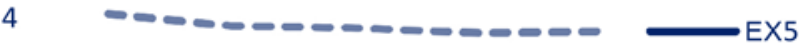

2

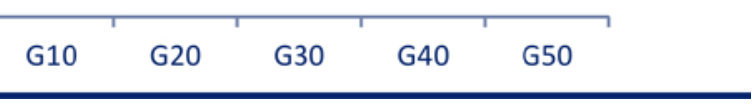

Figura 2: Comparaçáo entre os melhores indivíduos obtidos a cada 10 geraçôes. Elaborado pelos autores. 
da superfície e o dimensionamento das aberturas). A primeira abordagem foi empregada nos quatro primeiros experimentos, sendo utilizadas duas formas como referência para a superfície da cobertura, uma curvilínea e outra linear. Cada uma delas foi testada considerando duas orientaçôes diferentes para as aberturas (Norte e Oeste). Os resultados obtidos permitiu identificar qual das orientaçóes foi a mais favorável para o local, sendo adotada para a realizaçáo do quinto experimento. Neste, foi empregada a segunda abordagem, tornando paramétricas as curvas definidoras da superfície da cobertura e a variação das dimensóes das aberturas, ambas controladas automaticamente pelos $\mathrm{AE}$, permitindo buscar e testar as diferentes soluçôes através da sua eficiência.

As superfícies utilizadas nos cinco experimentos serviram de referências para a definição de uma malha dividida em 12 × 6 módulos. Essa malha foi adotada como base para a construção de uma estrutura tridimensional triangulada, utilizando os vértices e as mediatrizes das laterais dos módulos como pontos de conexão dos elementos estruturais. Alguns desses elementos são os responsáveis pelo dimensionamento das aberturas (os espaçadores), e foram posicionados em todos os módulos da estrutura triangular (Figura 1). O seu tamanho varia em função da distância entre a posição desses espaçadores na malha e o ponto de atração mais próximo. Desta forma, dois pontos de atração, movidos automaticamente através dos AE, foram distribuídos na superfície para explorar diferentes posiçóes e gerar diversidade nas dimensôes das aberturas. Isso garantiu maior flexibilidade ao sistema, auxiliando os $\mathrm{AE}$ a encontrar as melhores soluçóes para o problema, pois quanto maior for a distância entre os espaçadores e os pontos, maiores serão os espaçamentos gerados nos vãos, consequentemente obtendo as aberturas maiores; quanto menor for a distância, menores serão os vãos.

\section{Resultados}

A associação entre as diferentes variáveis que constituem o sistema generativo evolutivo contribuíram para a definição de um sistema parametrizado que gerou um amplo espaço de soluçóes, auxiliando na geraçáo de resultados formais inesperados e na obtençáo de soluçóes otimizadas com relação ao sombreamento e as aberturas. Foram geradas, de maneira automatizada, em cada um dos experimentos aproximadamente 2550 possibilidades para a cobertura ( 50 geraçốes com 50 indivíduos cada, mais os 50 indivíduos a mais na geração inicial).

A avaliação dos resultados obtidos nos três experimentos foi realizada a partir de dois critérios, a maior área de sombreamento projetada pela cobertura e o maior valor obtido pela somatória do comprimento de todos os vãos das aberturas da superfície. Esses dois critérios correspondem a um valor numérico obtido pelo próprio código que ao serem somados dão origem ao valor de fitness, correspondendo ao índice utilizado para a classificação das alterativas de projeto. Para efeito de análise, o valor de fitness obtido nos cinco experimentos (EX) possibilitou a seleção das cinco melhores soluçôes obtidas a cada dez geraçóes (Figura 2), permitindo um estudo mais aprofundado, considerando independentemente a área de sombreamento e a somatória das distâncias dos comprimentos dos vãos. Dessa forma, a partir daqueles critérios e dos indivíduos

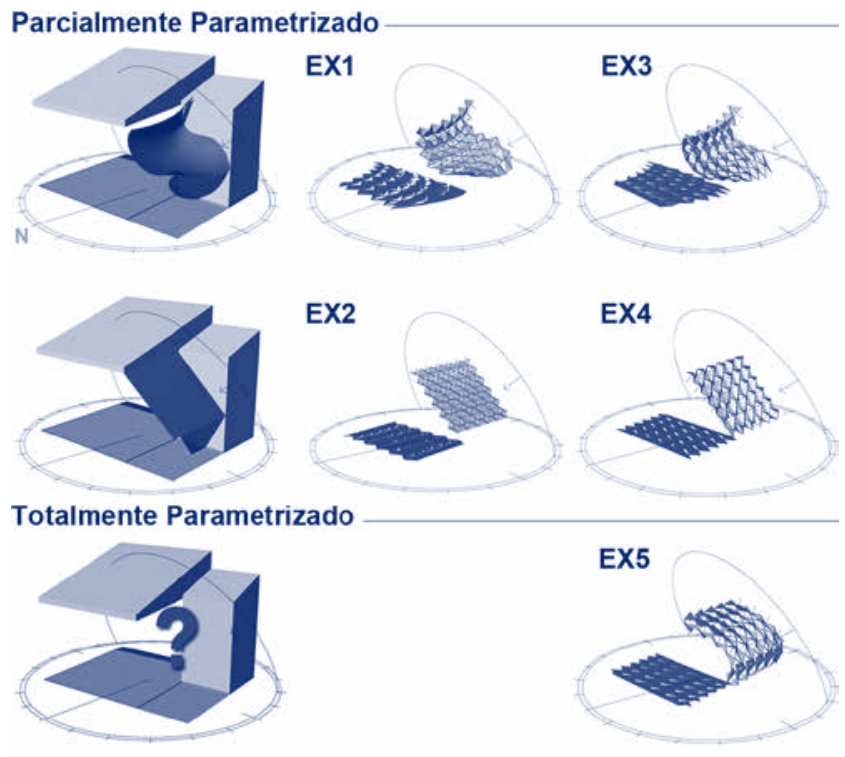

Figura 3: Diferentes abordagens e experimentos (EX). Elaborado pelos autores.

selecionados para a análise foi possível realizar a comparação entre os experimentos.

Os experimentos EX1 e EX 2 (Figura 3) foram realizados com as aberturas direcionadas para o Oeste, o que talvez explique possuírem as soluçôes com a menor área de sombreamento. Ao analisar as suas curvas nos gráficos de área de sombreamento e dimensão dos vãos é possível verificar uma situação de inversão, ou seja, o maior sombreamento com o menor valor para a somatória dos

Figura 4: Soluçâo obtida no experimento EX5 com o maior fitness. Elaborado pelos autores.

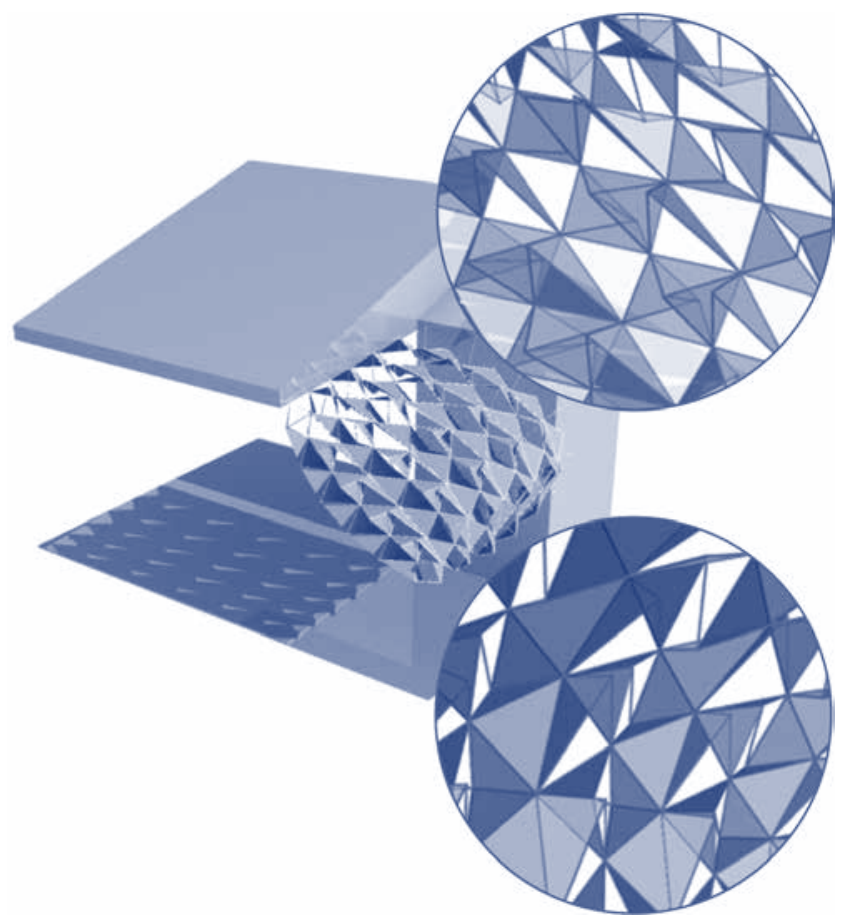


vãos e vice-versa. Isso demonstra que nesses dois experimentos os $\mathrm{AE}$ encontraram dificuldades para obter uma relação de equilíbrio entre o sombreamento e as aberturas.

A mudança da orientação das aberturas para o Norte favoreceu os resultados obtidos nos experimentos EX3 e EX4 (Figura 3) em ambos os critérios, possibilitando aos AE obter resultados mais satisfatórios do que os experimentos anteriores. Com relação à área de sombreamento o EX3 possui uma pequena vantagem sobre o EX4, embora possuam praticamente o mesmo valor. A maior diferença entre os dois está na somatória dos comprimentos dos vãos, sendo maior no EX3. Isso ocorre porque ele possui uma superfície curva como base para a cobertura, conseguindo gerar diferentes ângulos para as aberturas, devido a sua irregularidade, desviando da incidência solar direta, criando maiores áreas de sombreamento, como consequência, obtendo maiores comprimentos para as aberturas. Já a regularidade da superfície plana do EX4 dificultou os AE de encontrar zonas de sombreamento, uma vez que não existia curvatura, mantendo os pontos de atraçáo isolados em uma região da superfície gerando vãos mínimos para as aberturas. Dessa forma, ao elaborar o experimento EX5, sob a abordagem totalmente paramétrica, foi possível pressupor a geração de uma superfície curva.

Esse experimento, o EX5, demonstrou um grande nível de evolução durante a execuçáo dos AE, apresentando um aumento no valor do fitness de $9,6 \%$, enquanto que os outros variaram entre 0,3\% e 2,5\%. Com relação à área de sombreamento, ele apresentou um acréscimo de 10,2\% na área final, já os outros experimentos ficaram entre $0,46 \%$ e $1,66 \%$ (o EX1 possuiu um decréscimo de $8,29 \%)$. Na somatória dos comprimentos dos vãos, o experimento EX5 apresentou um acréscimo de 5,2\%, taxa inferior quando comparada aos valores de $42,3 \%$ do EX1 e $11,5 \%$ do EX3, mas que provavelmente justifica possuírem a menor área de sombreamento. As comparaçôes realizadas entre as curvas dos gráficos possibilitam entender a evolução, mas o que define a melhor soluçáo são os valores obtidos no final da execuçáo dos algoritmos. Dessa forma, foram avaliados apenas os melhores indivíduos de cada experimento obtidos na última geração (G50), sendo considerada a maior área de sombreamento e a maior somatória para o comprimento dos vãos. Com relação à somatória dos vãos, os indivíduos dos experimentos EX1 e EX3 possuem o mesmo valor de 12,4m, não muito distante dos 11,9m do EX5. A área de sombreamento apresenta um distanciamento maior entre os dois primeiros indivíduos, correspondendo a $27,8 \mathrm{~m}^{2}$ para o EX5 e $24,1 \mathrm{~m}^{2}$ para o EX3, fazendo deste critério o determinante para a escolha da melhor solução.
Isso permite verificar que o EX5, que possui a abordagem da parametrização total, mostrou-se mais eficiente, gerando a maior área de sombreamento, índice de aberturas satisfatório e, inclusive, a geração de uma forma inesperada (Figura 5).

\section{Conclusão}

$\mathrm{O}$ experimento permitiu concluir que o uso de um sistema generativo evolutivo na fase inicial do desenvolvimento projetual pode tornar o processo de busca de soluçóes otimizadas mais eficiente, de maneira exploratória e investigativa através de constantes reconfiguraçóes das variáveis ou dos elementos que compóem o projeto. Ao observar as curvas dos gráficos e comparar o comportamento dos experimentos durante a execução dos $\mathrm{AE}$ possibilitou o maior entendimento sobre o projeto. Pois as taxas encontradas e as curvas dos gráficos tornaram mais evidentes o comportamento das variáveis adotadas, das relaçôes definidas e dos critérios adotados para a seleção dos melhores indivíduos. $\mathrm{O}$ entendimento sobre o projeto ganha outra dimensáo e o projetar assume um novo status; a informação passa a ser a matéria prima a ser gerenciada, manipulada, avaliada e tratada, apresentando um peso considerável durante todo o processo de projeto.

\section{Agradecimentos}

Os autores agradecem à FAPESP pela concessão da bolsa de doutorado de Jarryer A. Martino, processo 2012/18112-7.

\section{Referências}

Alexander, C. et al. (2013). Uma linguagem de padróes. Porto Alegre: Bookman.

Bentley, P. J. (1999). Evolutionary Design by Computers. San Francisco: Morgan Kaufmann Publishers Inc.

Eiben, A. E.; Smith, J. E. (2010). Introduction to evolutionary computing. Berlin: Springer-Verlag.

Floreano, D.; Mattiussi, C. (2008). Bio-inspired artificial intelligence: theories, methods, and technologies. Cambridge: The MIT Press.

Groat, L.; Wang, D. (2013). Architectural research Methods. 2ed. New York: Wiley.

Kallel, L. et al (Ed). (2001). Theoretical aspects of evolutionary computing. Berlin; New York: Springer.

Terzidis, K. (2009). Algorithmic architecture. Oxford: Elsevier.

Woodbury, R. (2010). Elements of parametric design. New York: Routledge. 